\title{
Níveis de farelo de algodão de alta energia em suplementos múltiplos para bovinos em pastejo: desempenho e avaliação econômica ${ }^{1}$
}

\section{Levels of high energy cottonseed meal in multiple supplements for grazing cattle: performance and economic evaluation}

\author{
Joanis Tilemahos Zervoudakis ${ }^{2 *}$; Rafaela Zanin ${ }^{3}$; \\ Lilian Chambó Rondena Pesqueira-Silva ${ }^{4}$; Luciana Keiko Hatamoto-Zervoudakis ${ }^{2}$; \\ Luciano da Silva Cabral'2; João Marcos Beltrame Benatti ${ }^{5}$; \\ Renata Pereira da Silva-Marques ${ }^{4}$
}

\section{Resumo}

O objetivo foi avaliar a substituição dos níveis de proteína do farelo de soja pela proteína do farelo de algodão (FA) de alta energia em suplementos múltiplos para bovinos de corte em pastejo no período seco do ano sobre o ganho médio diário (GMD) e viabilidade econômica. Foram utilizados 20 novilhos Nelores com peso médio inicial de $351,25 \pm 35,38 \mathrm{~kg}$ e idade média de $24 \pm 0,8$ meses, distribuídos em quatro piquetes de Brachiaria brizantha cv. Marandu com 1,6 ha cada em delineamento inteiramente casualizado com quatro suplementos e cinco animais para avaliar os seguintes suplementos: 0FA, 25FA e 50FA correspondentes ao nível de 0,25 e 50\% de farelo de algodão de alta energia em substituição ao farelo de soja, fornecidos na quantidade de $2 \mathrm{~kg} / \mathrm{animal} / \mathrm{dia}$, além do suplemento exclusivo com mistura mineral ad libitum (MM). Verificou-se maior ganho de peso médio diário (GMD) $(\mathrm{P}<0,0001)$ para animais recebendo suplementação concentrada $(0,62 \mathrm{~kg} /$ animal/dia $)$ em comparação aqueles do grupo controle $(-0,020 \mathrm{~kg} / \mathrm{animal} / \mathrm{dia})$. O suplemento $25 \mathrm{FA}$ proporcionou maior $(\mathrm{P}<0,0001) \mathrm{GMD}(0,75 \mathrm{~kg} /$ animal $\left./ \mathrm{dia}^{-1}\right)$ em relação ao suplemento 50FA $\left(0,60 \mathrm{~kg} / \mathrm{animal} / \mathrm{dia}^{-1}\right)$. O GMD dos animais suplementados com $0 \mathrm{FA}\left(0,53 \mathrm{~kg} / \mathrm{animal} / \mathrm{dia}^{-1}\right)$ não diferiu $(\mathrm{P}>0,0001)$ do $\mathrm{GMD}$ dos novilhos que receberam suplemento com 25FA $\left(0,75 \mathrm{~kg} /\right.$ animal $\left./ \mathrm{dia}^{-1}\right)$ e com 50FA $\left(0,60 \mathrm{~kg} / \mathrm{animal} / \mathrm{dia}^{-1}\right)$. O suplemento $25 \mathrm{FA}$ apresentou maior retorno econômico sobre o capital investido no período. A utilização de farelo de algodão de alta energia em nível de substituição de $25 \%$ do farelo de soja em suplementos múltiplos proporcionou maior ganho de peso de bovinos e melhor viabilidade econômica.

Palavras-chave: Ganho de peso, marandu, período seco, proteína, suplementação

\footnotetext{
Abstract

The objective was to evaluate the substitution levels of protein from soybean meal by high energy cottonseed (CS) meal in multiple supplements for beef cattle grazing in the dry season on the average daily gain (ADG) and economic viability. Twenty Nellore steers with initial body weight of $351.25 \pm 35.38 \mathrm{~kg}$ and average initial age of $24 \pm 0.8$ months were used, divided into four paddocks of

${ }^{1}$ Parte da Dissertação de Mestrado em Ciência Animal, da segunda autora, Universidade Federal de Mato Grosso, UFMT, Cuiabá, MT.

${ }^{2}$ Profs., UFMT, Cuiabá, MT. E-mail: joanisz@yahoo.com.br; lukeiko@yahoo.com.br; lucianoufmt@gmail.com

${ }^{3}$ Me. em Ciência Animal, UFMT, Cuiabá, MT. E-mail: rafazanin@hotmail.com

${ }^{4}$ Discentes de Doutorado em Ciência Animal, UFMT, Cuiabá, MT. E-mail: lilianrondena@hotmail.com; renatinharps@hotmail.com

${ }^{5}$ Dr. em Zootecnia, Universidade Estadual Paulista "Julio de Mesquita Filho", UNESP, Jaboticabal, SP. E-mail: jonizoo@yahoo. com.br

*Autor para correspondência
} 
Brachiaria brizantha $\mathrm{cv}$. Marandu with 1.6 ha each incompletely randomized design with four animals and five supplements to assess the following supplements: 0CS, 25CS and 50CS corresponding to the level of 0,25 and $50 \%$ high energy cottonseed meal to replace the meal soybean, provided the amount of $2 \mathrm{~kg} / \mathrm{animal} / \mathrm{day}$, which were compared to mineral mixture (MM). The supplement 25CS provided higher $(\mathrm{P}<0.0001)$ ADG $\left(0.75 \mathrm{~kg} /\right.$ animal day $\left.^{-1}\right)$ compared to supplement $50 \mathrm{CS}\left(0.60 \mathrm{~kg} / \mathrm{animal} / \mathrm{day}^{-1}\right)$. The ADG of animals supplemented with $0 \mathrm{CS}\left(0.53 \mathrm{~kg} / \mathrm{animal} / \mathrm{day}^{-1}\right)$ did not differ $(\mathrm{P}<0.0001)$ of the ADG of the bulls receiving supplementation with $25 \mathrm{CS}\left(0.75 \mathrm{k} / \mathrm{animal} / \mathrm{day}^{-1}\right)$ and $50 \mathrm{CS}(0,60 \mathrm{~kg} / \mathrm{animal}$ / day-1). The 25CS supplement showed a higher economic return on invested capital in the period. The use of cottonseed meal high energy level of $25 \%$ replacement of soybean meal in multiple supplements provided greater weight gain of cattle and improved economic viability.

Key words: Cattle, dry period, marandu, protein, supplementation

\section{Introdução}

Os sistemas de produção de bovinos de corte no Brasil têm sido desafiados, pelas mudanças nos setores do agronegócio, a produzir carne de boa qualidade (com preço mais acessível) de forma eficiente, competitiva e sustentável. Entretanto, os índices produtivos nacionais continuam baixos e podem ser atribuídos a variação entre o suprimento e a demanda de nutrientes pelos animais ao longo do ano devido à estacionalidade na produção forrageira, ou seja, no período seco do ano ocorre redução na produtividade e na qualidade das gramíneas tropicais, não permitindo desempenho constante dos animais ao longo do ano (REIS et al., 2012).

Para maximizar a utilização da forragem pelos bovinos no período seco, é necessário suprir as carências nutricionais dos microrganismos ruminais, favorecendo sua taxa de crescimento (SAMPAIO et al., 2010), condição que pode ser alcançada com a utilização de suplementos múltiplos (proteicoenergético), os quais proporcionarão o crescimento contínuo dos bovinos em pastejo.

Segundo Barros et al. (2014) a utilização de suplementos múltiplos permite ao animal melhor utilização dos recursos forrageiros, e aos sistemas de criação a ampliação do fluxo de produtos e maior eficiência de exploração de seu potencial produtivo.

Um ponto importante que deve ser ressaltado é o custo com os suplementos, uma vez que, os ingredientes tradicionais (milho e soja) são os mais utilizados na formulação dos suplementos concentrados fornecidos para bovinos em pastejo. No entanto, estes ingredientes possuem maior valor agregado por serem utilizados na alimentação humana. Sendo assim, aspectos econômicos e nutricionais dos alimentos alternativos utilizados para bovinos vêm sendo avaliados, de modo que possam viabilizar a produção intensiva de ruminantes suplementados com menores custos de produção (ZERVOUDAKIS et al., 2011).

O farelo de algodão é um potencial substituto do farelo de soja, visto que, é menos oneroso e possui maior quantidade de proteína não degradável no rúmen (PNDR) (NRC, 2001), o que acarreta em aumento no fluxo de proteína para o intestino delgado (COMMER et al., 1993; ZINN; OWENS, 1993). No entanto, o excesso de PNDR pode ocasionar deficiência de nitrogênio para a microbiota ruminal, reduzindo a eficiência de síntese de proteína microbiana e a digestibilidade ruminal dos nutrientes (DEWHURST; MERRY; DAVIES, 2000).

Deste modo, objetivou-se avaliar o desempenho produtivo e os custos de produção de novilhos de corte em pastejo na fase de recria, recebendo suplementos múltiplos com diferentes níveis de substituição do farelo de soja pelo farelo de algodão de alta energia durante o período seco do ano.

\section{Material e Métodos}

O experimento foi conduzido no Setor de Bovinocultura de Corte da Fazenda Experimental 
da Faculdade de Agronomia, Medicina Veterinária e Zootecnia da Universidade Federal de Mato Grosso, localizada no município de Santo Antônio do Leverger - MT, durante o período seco do ano, entre os meses de julho a setembro.

Foram utilizados 20 novilhos Nelores, não castrados, com idade média de $24 \pm 0.8$ meses e peso médio inicial de $351,25 \pm 35.38 \mathrm{~kg}$, mantidos em quatro piquetes de 1,6ha cada, formados por gramínea Brachiaria brizantha cv. Marandu, providos de bebedouros e cochos cobertos para fornecimento do suplemento, cujas dimensões permitiram acesso de todos os animais simultaneamente. Visando minimizar a influência de possíveis variações de ambiente, cada lote permaneceu em cada piquete por 14 dias procedendo-se, ao final desse período, à rotação entre eles.

Os suplementos (Tabela 1) foram formulados com níveis de substituição parcial do farelo de soja pelo farelo de algodão (FA): 0\% (0FA), 25\% (25FA) e $50 \%$ (50FA), fornecidos na quantidade de $2 \mathrm{~kg} /$ animal/dia às 10 horas da manhã e um suplemento controle somente com mistura mineral comercial (MM) ad libitum.

Tabela 1. Composição dos suplementos em $\mathrm{g} / \mathrm{kg}$ com diferentes níveis de inclusão do farelo de algodão de alta energia expressa com base na matéria seca e custo do quilograma $(\mathrm{kg})$ dos ingredientes.

\begin{tabular}{|c|c|c|c|c|c|}
\hline \multirow{2}{*}{ Ingrediente } & \multicolumn{4}{|c|}{ Suplemento } & \multirow{2}{*}{$\begin{array}{c}\text { Custo } \\
\text { (R\$/kg) }\end{array}$} \\
\hline & $\mathrm{MM}^{1}$ & $0 \mathrm{FA}^{2}$ & $25 \mathrm{FA}^{3}$ & $50 \mathrm{FA}^{4}$ & \\
\hline Casquinha de Soja & --- & 490,0 & 427,0 & 365,0 & 0,28 \\
\hline Farelo de Soja & --- & 420,0 & 315,0 & 210,0 & 0,50 \\
\hline Farelo de Algodão de Alta Energia & --- & --- & 165,0 & 330,0 & 0,34 \\
\hline Ureia & --- & 36,0 & 38,7 & 40,5 & 1,92 \\
\hline Sulfato de Amônio & --- & 4,0 & 4,3 & 4,5 & 12,6 \\
\hline Sal Mineral & 1000,0 & 50,0 & 50,0 & 50,0 & 1,17 \\
\hline
\end{tabular}

${ }^{1}$ Suplemento mineral comercial; Níveis de garantia: cálcio $198 \mathrm{~g}$; fósforo $60 \mathrm{~g}$; sódio $117 \mathrm{~g}$; magnésio $5,1 \mathrm{~g}$; enxofre $12,6 \mathrm{~g}$; iodo $17,7 \mathrm{mg}$; ferro $425 \mathrm{mg}$; selênio $10,4 \mathrm{mg}$; cobalto $80 \mathrm{mg}$; manganês $527 \mathrm{mg}$; flúor $600 \mathrm{mg}$; cobre $1.000 \mathrm{mg}$ e zinco $3.000 \mathrm{mg}$;; ${ }^{2} 0 \%$ da proteína do farelo de soja pelo farelo de algodão de alta energia; ${ }^{3} 25 \%$ da proteína do farelo de soja pelo farelo de algodão de alta energia; ${ }^{4} 50 \%$ da proteína do farelo de soja pelo farelo de algodão de alta energia.

Fonte: Elaborado pelos autores.

O experimento foi estruturado em delineamento inteiramente casualizado (DIC), sendo constituído de três períodos experimentais de 28 dias cada, perfazendo um total de 84 dias, sendo que o ganho médio diário e o ganho de peso corporal foram determinados pela diferença entre o peso corporal final e o inicial, com jejum de sólidos de 14 horas. A cada 28 dias foram realizados pesagem sem jejum dos animais.

A coleta de forragem foi realizada no inicio de cada período experimental, através do corte à $5 \mathrm{~cm}$ do solo de cinco áreas delimitadas por um quadrado metálico de $0,25 \mathrm{~m}^{2}$, escolhidos aleatoriamente.
Após a coleta, as amostras de forragem de cada piquete foram pesadas e homogeneizadas. Após isso, retirou-se duas alíquotas compostas: uma para avaliação da massa de forragem (MF)/ha e a outra para fracionamento dos componentes estruturais da planta folha posterior análise das disponibilidades por hectare de matéria seca de lâmina foliar verde, lâmina foliar seca, pseudocolmo verde e pseudocolmo seco. A amostragem da forragem consumida pelos animais foi obtida via simulação manual do pastejo, realizada no início de cada período experimental. As amostras foram imediatamente pesadas após as coletas e congeladas a $-20^{\circ} \mathrm{C}$, e 
posteriormente, descongeladas e secas em estufa de ventilação forçada a $65{ }^{\circ} \mathrm{C}$, moídas em moinho tipo Willey (com peneira de malha de 1,0 mm), para posterior analises químico-bromatológicas.

Das amostras destinadas à estimação da MF, calculou-se o percentual de matéria seca potencialmente digestível (MSpD). Esse resultado foi obtido por intermédio do resíduo insolúvel em detergente neutro indigerível (FDNi) avaliado após incubação in situ das amostras por 240 horas, segundo Casali et al. (2008), seguindo a equação proposta por Paulino et al. (2006).

As amostras de ingredientes, concentrados e forragem foram analisadas para determinações da matéria seca (MS), matéria orgânica (MO), proteína bruta (PB), fibra em detergente neutro (FDN), fibra em detergente ácido (FDA), extrato etéreo (EE) e matéria mineral (MM), de acordo com descrições de Silva e Queiroz (2002). A determinação do nitrogênio insolúvel em detergente neutro (NIDN) e ácido (NIDA) seguiu os métodos descritos por Van Soest, Robertson e Lewis (1991). Os teores de carboidratos totais dos alimentos (CT) foram calculados segundo Sniffen et al. (1992): CT = $100-(\% \mathrm{~PB}+\% \mathrm{EE}+\%$ Cinzas $)$. Com base na composição química dos alimentos, os teores de nutrientes digestíveis totais (NDT) foram estimados de acordo com Capelle et al. (2001), sendo NDT= 83,79-0,4171 x FDN (\%).

A avaliação econômica dos suplementos foi realizada tendo em vista a remuneração do capital investido, obtido dividindo-se a margem de lucro pelas despesas envolvidas no processo de suplementação. A receita foi obtida através da multiplicação do ganho em equivalente carcaça em arroba (@) pelo valor da@na região (R\$ $86,70)$, e as despesas foram obtidas através do custo total com pasto $(15 \%$ do valor médio da arroba durante o período experimental mais o custo operacional e custos com sanidade, mãode-obra entre outros (R\$ 0,128/dia)), custo com suplemento considerando o valor de $\mathrm{R} \$ 1,17 / \mathrm{kg}$ de mistura mineral e $\mathrm{R} \$ 0,48 ; \mathrm{R} \$ 0,47 ; \mathrm{R} \$ 0,46 / \mathrm{kg}$ de suplemento, respectivamente para 0FA, 25FA e 50FA, e custo com os animais com atualização do início até o fim do período experimental em relação à taxa de juros \{Preço do novilho aos 24 meses de idade sob a taxa de juros $(0,6 \% /$ mês $)\}$. Todas as cotações empregadas foram tomadas na região e no período em que se conduziu este experimento.

Os resultados foram interpretados estatisticamente por meio de análises de variância. O peso corporal inicial foi adotado como covariável (SNEDECOR; COCHRAN, 1989). Para as comparações dos suplementos adotou-se o teste de médias Students-Newman-Keulls (SNK). Todos os procedimentos estatísticos foram conduzidos por intermédio do programa estatístico SAS (1999), adotando-se $\alpha$ de 0,05 .

\section{Resultados e Discussão}

As médias de massa de forragem (MF), disponibilidades de matéria seca potencialmente digestível (MSpD), de matéria seca de lâmina foliar verde, lâmina foliar seca, pseudocolmo verde e pseudocolmo seco observadas durante o período experimental foram de 5,$25 ; 3,15 ; 0,51 ; 1,47 ; 1,77$ e 1,51 toneladas ( $\mathrm{t}$ ) de $\mathrm{MS} / \mathrm{ha}$, respectivamente.

Segundo Silva et al. (2009) deve-se garantir pelo menos $4.500 \mathrm{~kg}$ de matéria seca total/ha para não limitar o consumo dos animais. Sendo assim, os valores encontrados neste experimento para massa de forragem contribuíram para ganho de peso dos novilhos no período seco. Além disso, a oferta de matéria seca potencialmente digestível (MSpD) para os animais durante o período experimental foi superior (10 kg de MSpD/100 kg de peso corporal (PC) ao recomendado por Paulino et al. (2006) de 4 a $5 \mathrm{~kg}$ de $\mathrm{MSpD} / 100 \mathrm{~kg}$ de PC para proporcionar seletividade no pastejo dos animais e ganhos individuais satisfatórios, sem comprometer o ganho por área. 
O aumento na disponibilidade de MS da forragem pode maximizar o seu consumo, porém a sua digestibilidade passa a ser o fator limitante (REIS et al., 2009). Verifica-se que a forragem disponível aos animais durante o período experimental apresentou qualidade condizente com o período seco, uma vez que, possuía baixo teor de proteína $(5,59 \%)$ e alto teor de fibra em detergente neutro $(79,39 \%$ de FDN) (Tabela 2), o que poderia ocasionar lentas taxas de digestão ruminal (MOREIRA et al., 2004) e consequentemente redução no consumo de matéria seca (DETMANN et al., 2011) e no desempenho animal (BARROS et al., 2014).

Tabela 2. Composição bromatológica dos suplementos e da forragem obtida via simulação manual do pastejo.

\begin{tabular}{|c|c|c|c|c|}
\hline \multirow{2}{*}{ Variável } & \multicolumn{3}{|c|}{ Suplemento } & \multirow{2}{*}{ B. brizanta ${ }^{l}$} \\
\hline & OFA $^{5}$ & $25 \mathrm{FA}^{6}$ & $50 \mathrm{FA}^{7}$ & \\
\hline Matéria seca total & 917,8 & 926,4 & 931,8 & 425,5 \\
\hline Matéria orgânica ${ }^{2}$ & 904,6 & 907,4 & 942,3 & 940,0 \\
\hline Proteína bruta ${ }^{2}$ & 381,6 & 376,0 & 367,6 & 55,9 \\
\hline Extrato etéreo $^{2}$ & 8,8 & 8,5 & 8,5 & 12,1 \\
\hline Matéria mineral $^{2}$ & 95,4 & 92,6 & 57,7 & 60,0 \\
\hline Carboidratos totais ${ }^{2}$ & 514,1 & 522,8 & 568,0 & 843,5 \\
\hline Fibra em detergente neutro ${ }^{2}$ & 625,2 & 639,3 & 651,4 & 793,9 \\
\hline Fibra em detergente ácido ${ }^{2}$ & 384,8 & 408,8 & 430,4 & 473,7 \\
\hline Fibra em detergente neutro indigestível ${ }^{22}$ & 159,5 & 188,2 & 214,1 & 380,8 \\
\hline Nitrogênio insolúvel em detergente neutro ${ }^{3}$ & 127,2 & 136,6 & 143,2 & 399,4 \\
\hline Nitrogênio insolúvel em detergente ácido ${ }^{3}$ & 127,8 & 134,4 & 138,2 & 228,7 \\
\hline Nutrientes digestíveis totais ${ }^{4}$ & 577,1 & 571,2 & 566,2 & 491,2 \\
\hline
\end{tabular}

${ }^{1}$ Simulação do pastejo; ${ }^{2} \mathrm{em} \mathrm{g} / \mathrm{kg} ;{ }^{3} \mathrm{~g} / \mathrm{kg}$ de $\mathrm{N}$ total; ${ }^{4}$ Estimado segundo Capelle et al. (2001): NDT= 83,79 - 0,4171 x FDN (\%); ${ }^{5} 0 \mathrm{FA}=0 \%$ da proteína do farelo de soja pelo farelo de algodão de alta energia; ${ }^{6} 25 \mathrm{FA}=25 \%$ da proteína do farelo de soja pelo farelo de algodão de alta energia; ${ }^{750 F A}=50 \%$ da proteína do farelo de soja pelo farelo de algodão de alta energia

Fonte: Elaborado pelos autores.

Segundo Lazzarini et al. (2009) valores de PB menores que 7\% impossibilitam crescimento adequado dos microrganismos ruminais comprometendo a fermentação dos carboidratos fibrosos, podendo resultar em prejuízos no desempenho. Sendo assim, há a necessidade do uso da suplementação proteica para suprir os nutrientes deficientes na forragem e potencializar a utilização da mesma pelos animais, proporcionando assim, maior ganho de peso.

Neste contexto, o desempenho animal foi influenciado positivamente pelo aporte proteico dos suplementos, possibilitando assim o sincronismo entre os compostos nitrogenados e energia no ambiente ruminal, pois verifica-se maior ganho de peso médio diário (GMD) $(\mathrm{P}<0,0001)$ para animais recebendo suplementação concentrada $(0,62 \mathrm{~kg} /$ animal/dia) em comparação aqueles do grupo controle, os quais perderam peso $(-0,020 \mathrm{~kg} / \mathrm{animal} /$ dia) (Tabela 3).

$\mathrm{O}$ aumento no ganho de peso dos animais suplementados pode ser justificado pela maior quantidade de substrato disponibilizado para os microrganismos ruminais. A perda de peso no período seco do ano é considerada a principal entrave, quando o objetivo é abater animais jovens, isto diminui a rentabilidade do sistema de produção, uma vez que, há necessidade desses animais 
permanecerem mais tempo na propriedade para atingir o peso satisfatório para o abate.

O suplemento com $25 \%$ de substituição do farelo de soja pelo farelo de algodão de alta energia (25FA) proporcionou maior GMD $(0,75 \mathrm{~kg} / \mathrm{animal} / \mathrm{dia}) \mathrm{em}$ relação ao suplemento 50FA $(0,60 \mathrm{~kg} / \mathrm{animal} / \mathrm{dia})$. Isto possivelmente é devido ao efeito associativo dos ingredientes farelo de soja (FS) e farelo de algodão, uma vez que, o FS é rico em PDR, a qual é fonte de nitrogênio para os microrganismos ruminais crescer e sintetizar proteína microbiana (VAN SOEST,
1994), sendo esta a melhor fonte para atender os requerimentos de aminoácidos do animal, tendo em vista que, a mesma é semelhante à proteína dos tecidos do animal quanto à composição aminoacídica (VERBIC, 2002). Além disso, o farelo de algodão alta energia apresenta menor degradabilidade da proteína em relação ao farelo de soja, resultando em maior aporte de PNDR chegando ao intestino, o que favorece o desempenho animal após atender os requerimentos em compostos nitrogenados dos microrganismos ruminais.

Tabela 3. Peso corporal inicial (PCi), peso corporal final (PCf), valores médios para ganho de peso total (GPT) e ganho médio diário (GMD) em função do grupo controle (mistura mineral $=\mathrm{MM}$ ) e dos níveis de inclusão do farelo de algodão substituindo farelo de soja nos suplementos.

\begin{tabular}{lccccc}
\hline \multirow{2}{*}{ Variável } & \multicolumn{4}{c}{ Suplemento } & \multirow{2}{*}{ Valor de P } \\
\cline { 2 - 5 } & MM $^{1}$ & $0 \mathrm{FA}^{2}$ & $25 \mathrm{FA}^{3}$ & $50 \mathrm{FA}^{4}$ & \\
\hline PCi (kg/animal) & $354,20 \pm 16,23$ & $349,80 \pm 24,42$ & $350,80 \pm 30,06$ & $350,20 \pm 17,88$ & 0,2822 \\
PCf (kg/animal) & $352,60 \pm 15,08$ & $394,00 \pm 29,80$ & $413,80 \pm 32,06$ & $400,40 \pm 17,31$ & - \\
GPT (kg/animal) & $-1,60 \pm 3,53$ & $44,20 \pm 6,12$ & $63,00 \pm 5,59$ & $50,20 \pm 4,69$ & - \\
GMD (kg/animal/dia) & $-0,02 \pm 0,04 \mathrm{c}$ & $0,53 \pm 0,07 \mathrm{ab}$ & $0,75 \pm 0,07 \mathrm{a}$ & $0,60 \pm 0,06 \mathrm{~b}$ & $<0,0001$ \\
\hline
\end{tabular}

Valores seguidos de letras iguais na linha, não diferem entre si pelo teste SNK a $5 \%$ de significância. ${ }^{1} \mathrm{MM}=$ suplemento mineral comercial; ${ }^{2} 0 \mathrm{FA}=0 \%$ da proteína do farelo de soja pelo farelo de algodão de alta energia; ${ }^{3} 25 \mathrm{FA}=25 \%$ da proteína do farelo de soja pelo farelo de algodão de alta energia; ${ }^{4} 50 \mathrm{FA}=50 \%$ da proteína do farelo de soja pelo farelo de algodão de alta energia.

Fonte: Elaborado pelos autores.

Adicionalmente, verifica-se que o ganho de peso diário dos animais suplementados com 0FA $(0,53 \mathrm{~kg} /$ animal/dia) não apresentou diferença do GMD dos novilhos que receberam suplemento com 25FA $(0,75 \mathrm{~kg} / \mathrm{animal} / \mathrm{dia})$ e com $50 \mathrm{FA}(0,60 \mathrm{~kg} / \mathrm{animal} /$ dia). Isto possivelmente é devido o suplemento 0FA apresentar maior teor de PDR em relação aos demais suplementos, favorecendo a síntese de proteína microbiana e consequentemente o desempenho animal. Além disso, quando aumentou a substituição do farelo de soja pelo farelo de algodão em 50\% no suplemento (50FA) houve redução numérica no ganho de peso dos animais. Este fato justificase possivelmente pela maior inclusão do farelo de algodão, ou seja, o suplemento $50 \mathrm{FA}$ pode ter apresentado excesso de PNDR, o que ocasionou deficiência de nitrogênio para a microbiota ruminal, reduzindo a eficiência de síntese de proteína microbiana, digestibilidade ruminal dos nutrientes e desempenho animal (DEWHURST; MERRY; DAVIES, 2000).

De acordo com Silva-Marques et al. (2015) avaliações do custo de produção são tão importante quanto à obtenção do ganho de peso dos animais, visto que, são parâmetros utilizados pelos pecuaristas para continuar ou não com essas estratégias de suplementação. Deste modo, é importante saber qual será o investimento necessário para a produção de $1 \mathrm{~kg}$ de peso corporal adicional. 
Pode-se verificar pelos índices econômicos (Tabela 4), que o fornecimento de apenas mistura mineral no período seco do ano para bovinos em pastejo não proporciona ganho de peso adequado, este fato resulta em menor receita $(\mathrm{R} \$ 1.080,32)$ com a venda dos animais. Apesar do menor investimento com este tipo de suplementação a remuneração sobre o capital investido é negativa $(\mathrm{R} \$-3,46)$.
Os suplementos $0 \%, 25 \%$ e $50 \%$ de substituição do farelo de soja por farelo de algodão proporcionaram acréscimo adicional no peso corporal dos animais de 0,273, 0,385 e 0,309 kg/ animal/dia por $\mathrm{kg}$ de suplemento consumido, sendo assim os desempenhos proporcionados pela suplementação concentrada foram suficientes para abonar os custos com suplementação.

Tabela 4. Indicadores econômicos de produção animal em função dos níveis de inclusão do farelo de algodão $(0 \%$, $25 \%$ e $50 \%$ ) substituindo farelo de soja em suplementos múltiplos.

\begin{tabular}{|c|c|c|c|c|}
\hline \multirow{2}{*}{ Variável } & \multicolumn{4}{|c|}{ Suplemento } \\
\hline & MM & 0FA & $25 \mathrm{FA}$ & 50FA \\
\hline Peso Corporal Inicial (kg) & 354,2 & 349,8 & 350,8 & 350,2 \\
\hline Peso Corporal Final & 352,6 & 394 & 413,8 & 400,4 \\
\hline Ganho de Peso Total (kg) & $-1,6$ & 44,2 & 63,0 & 50,2 \\
\hline Ganho de Peso Médio Diário (kg/dia) & $-0,019$ & 0,526 & 0,750 & 0,598 \\
\hline Duração do Período experimental (mês) & 2,80 & 2,80 & 2,80 & 2,80 \\
\hline Idade ao abate (meses) & 26,80 & 26,80 & 26,80 & 26,80 \\
\hline Consumo de suplemento (kg/dia) & 0,10 & 2,00 & 2,00 & 2,00 \\
\hline Custo do suplemento $(\mathrm{R} \$ / \mathrm{kg})$ & 1,17 & 0,48 & 0,47 & 0,46 \\
\hline Investimento com Suplemento (R $\$ / 84 \mathrm{dias})^{1}$ & 9,83 & 80,64 & 78,96 & 77,28 \\
\hline Investimento com Pasto ( $\mathrm{R} \$ / 84 \mathrm{dias})^{2}$ & 40,46 & 40,46 & 40,46 & 40,46 \\
\hline Atualização do Preço Novilho $(\mathrm{R} \$)^{3}$ & 1068,75 & 1068,75 & 1068,75 & 1068,75 \\
\hline Investimento Total $(\mathrm{R} \$)^{4}$ & 1119,07 & 1189,85 & 1188,17 & 1186,49 \\
\hline Receita $(\mathrm{R} \$)^{5}$ & 1080,32 & 1207,10 & 1267,82 & 1226,76 \\
\hline Lucro $(\mathrm{R} \$)^{6}$ & $-38,74$ & 17,25 & 79,64 & 40,27 \\
\hline Remuneração capital investido no período $(\%)^{7}$ & $-3,46$ & 1,45 & 6,70 & 3,39 \\
\hline Remuneração mensal do capital investido $(\%)^{8}$ & $-1,24$ & 0,52 & 2,39 & 1,21 \\
\hline Peso corporal adicional (PCA) $(\mathrm{kg} / \mathrm{dia})^{9}$ & - & 0,545 & 0,769 & 0,617 \\
\hline Receita $(\mathrm{RC})$ por $\mathrm{kg}$ de PCA $(\mathrm{R} \$)^{10}$ & - & 3,00 & 3,00 & 3,00 \\
\hline Receita do PCA em 84 dias $(\mathrm{R} \$)^{11}$ & - & 137,34 & 193,78 & 155,48 \\
\hline Resposta produtiva $(\mathrm{RP})(\mathrm{kg} / \mathrm{kg})^{12}$ & - & 0,273 & 0,385 & 0,309 \\
\hline Preço máximo do suplemento (PMS) $(\mathrm{R} \$ / \mathrm{kg})^{13}$ & - & 0,819 & 1,155 & 0,927 \\
\hline Custo suplementação/animal/dia $(\mathrm{R} \$)^{14}$ & - & 1,64 & 2,31 & 1,85 \\
\hline Retorno relativo $(\mathrm{R} \$)^{15}$ & - & 1,70 & 2,45 & 2,01 \\
\hline
\end{tabular}

${ }^{1}$ Consumo*duração do ciclo (meses)*30 dias*Custo do suplemento; ${ }^{2} 12 \%$ do valor médio da @ durante o período experimental + Custo operacional e outros custos $(=12 \% * 88,44+(0,128 *$ período experimental $)) ;$ Preço do novilho aos 24 meses (IMEA) (considerado 52\% de rendimento de carcaça *valor da @ de R $\$ 86,7) *[1+(0,6 \% \text { taxa de juros } / 100)]^{\wedge}$ duração do ciclo; ${ }^{4}$ Investimento pasto + investimento suplemento + atualização do preço do novilho; ${ }^{5}$ Venda dos novilhos considerado $52 \%$ de rendimento de carcaça *valor da @ de R \$ 88,38; ${ }^{6}$ Receita -Investimento total; ${ }^{7}$ Lucro/Investimento total*100; ${ }^{8}$ (Lucro/Investimento total*100)/duração do ciclo; ${ }^{9} \mathrm{Ganho}$ diferencial em relação aos animais suplementados com mistura mineral; ${ }^{10} \mathrm{RC}=(\mathrm{preço} \mathrm{da} \mathrm{@}(\mathrm{R} \$ 86,7) / 15 \mathrm{~kg}) * 0,52$ (rendimento carcaça); ${ }^{11} \mathrm{Receita}=(\mathrm{RC} * \mathrm{PCA} * 84$ dias $) ;{ }^{12} \mathrm{RP}=\mathrm{PCA} /$ consumo de suplemento; ${ }^{13} \mathrm{PMS}=\mathrm{RC} * \mathrm{RP} ;{ }^{14}(\mathrm{Consumo}$ de suplemento*PMS); ${ }^{15}$ Receita do PCA/custos da suplementação.

Fonte: Elaborado pelos autores. 
Observou-se ainda que o suplemento 25FA por ter proporcionado o maior ganho médio diário adicional $(0,769 \mathrm{~kg} /$ animal dia) aos animais recebendo apenas mistura mineral foi o que resultou em maior receita ( $\mathrm{R} \$ 1.267,82)$ com a venda dos animais, maior lucro (R\$79,64) e, portanto maior remuneração do capital investido no período ( $\mathrm{R} \$$ 2,45).

O menor desempenho econômico (R\$ 1,70) foi verificado para o suplemento OFA constituído pela fonte proteica farelo de soja, que se atribui não somente ao menor desempenho numérico $(0,545 \mathrm{~kg} /$ animal/dia), como também ao seu custo relativamente elevado $(\mathrm{R} \$ 0,48 / \mathrm{kg})$.

Dessa forma, quando se visa à terminação de animais no período seco os resultados de ganho médio diário para animais recebendo os suplementos 0FA, 25FA, 50FA comprovam a necessidade da suplementação para que os animais permaneçam por menos tempo na propriedade e consigam atingir o peso satisfatório para abate, proporcionando uma pecuária de ciclo curto e de maior retorno do capital investido. Além disso, apesar dos indicadores (Tabela 4) mostrarem o benefício direto da suplementação, esses não computam as vantagens com a antecipação da liberação das pastagens, sendo esta a principal vantagem em longo prazo da utilização da suplementação.

\section{Conclusões}

O fornecimento de suplementos múltiplos com substituição de $25 \%$ do farelo de soja pelo farelo de algodão alta energia para novilhos de corte em pastejo no período da seca proporciona desempenho e retorno financeiro positivo, demonstrando, portanto o potencial uso de suplementos com inclusão de farelo de algodão para sistemas intensivos de produção de carne bovina em pastejo.

\section{Referências}

BARROS, L. V.; PAULINO, M. F.; MORAES, E. H. B. K.; DETMANN, E.; ALMEIDA, D. M.; MARTINS, L. S.; SILVA, A. G.; LOPES, S. A.; MÁrQUEZ, D. E. C.; CARDENAS, J. E. G. Desempenho produtivo e nutricional de novilhas de corte em pastejo suplementadas no período da seca e/ou no período de transição seca-águas. Semina: Ciências Agrárias, Londrina, v. 35, n. 4, p. 26552672, 2014. Suplemento 1.

CAPELlE, E. R.; VALADARES FILHO, S. C.; COELHO DA SILVA, J. F.; CECON, P. R. Estimativas do valor energético a partir de características químicas e bromatológicas dos alimentos. Revista Brasileira de Zootecnia, Viçosa, MG, v. 6, n. 30, p. 1837-1856, 2001.

CASALI, A. O.; DETMANN, E.; PEREIRA, J. C.; HENRIQUES, L. T.; FREIAS, S. G.; PAULINO, F. Influencia do tempo de incubação e do tamanho de partículas sobre os teores de compostos indigestíveis em alimentos e fezes bovinas obtidos por procedimento in situ. Revista Brasileira de Zootecnia, Viçosa, MG, v. 37, p. 335-342, 2008.

COMMER, J. C.; AMOS, H. E.; FROETSCHEL, M. A.; RAGLAND, K. K.; WILliaMS, C. C. Effects of supplemental protein source on ruminal fermentation, protein degradation, and amino acid absorption in steers and on growth and feed efficiency in steers and heifers. Journal of Animal Science, Champaign, v. 71, n. 10, p. 3078-3086, 1993.

DETMANN, E.; QUEIROZ, A. C.; ZORZI, K.; MANTOVANI, H. C.; BAYÃO, G. F. V.; GOMES, M. P. C. Degradação in vitro da fibra em detergente neutro de forragem tropical de baixa qualidade em função da suplementação com proteína verdadeira e/ou nitrogênio não-proteico. Revista Brasileira de Zootecnia, Viçosa, MG, v. 40, n. 6, p. 1272-1279, 2011.

DEWHURST, R. J.; MERRY, D. R.; DAVIES, R. J. Microbial protein supply from the rumen. Animal Feed Science and Technology, Aberystwyth, v. 85, n. 1-2, p. 1-21, 2000.

LAZZARINI, I.; DETAMANN, E.; SAMPAIO. C. B.; PAULINO, M. F.; VALADARES FILHO, S. C.; SOUZA, M. A.; OLIVEIRA, F. A. Intake and 
digestibility in cattle fed low-quality tropical forage and supplemented with nitrogenous compounds. Revista Brasileira de Zootecnia, Viçosa, MG, v. 38, n. 10, p. 2021-2030, 2009.

MOREIRA, F. B.; PRADO, I. N.; CECATO U.; WADA, F. Y.; MIZUBUTI, I. Y. Forage evaluation, chemical composition, and in vitro digestibility of continuously grazed star grass. Animal Feed Science and Technology, Missouri, v. 113, n. 1-4, p. 239-249, 2004.

NATIONAL RESEARCH COUNCIL - NRC. Nutrients requirements of dairy cattle. $7^{\text {th }}$ ed. Washington: National Academy Press, 2001. 381 p.

PAULINO, M. F.; DETMANN, E.; VALADARES FILHO, S. C. Suplementação animal em pasto: energética ou protéica? In: SIMPÓSIO SOBRE MANEJO ESTRATÉGICO DA PASTAGEM, 3., 2006, Viçosa, MG. Anais... Viçosa, MG, 2006. p. 359-392.

REIS, R. A.; RUGGIERI, A. C.; CASAGRANDE, D. R.; PÁSCOA, A. G. Suplementação da dieta de bovinos de corte como estratégia de manejo das pastagens. Revista Brasileira de Zootecnia, Viçosa, MG, v. 38, p. 147-159, 2009. Suplemento Especial.

REIS, R. A.; RUGGIERI, A. C.; OLIVEIRA, A. A.; AZENHA, M. V.; CASAGRANDE, D. R. Suplementação como estratégia de produção de carne de qualidade em pastagens tropicais. Revista Brasileira de Saúde e Produção Animal, Salvador, v. 13, n. 3, p. 642-655, 2012.

SAMPAIO, C. B.; DETMANN, E.; PAULINO, M. F.; VALADARES FILHO, S. C.; SOUZA, M. A.; LAZZARINI, I.; PAULINO, P. V. R.; QUEIROZ, A. C. Intake and digestibility in cattle fed lowquality tropical forage and supplemented with nitrogenous compounds. Tropical Animal Health and Production, Edinburgh, v. 42, n. 6, p. 14711479, 2010.

SILVA, D. J.; QUEIROZ, A. C. Análise de alimentos: métodos químicos e biológicos. 3. ed. Viçosa, MG: Universidade Federal de Viçosa, 2002. 165 p.

SILVA, F. F.; SÁ, J. F.; SCHIO, A. R.; ÍTAVO, L. C. V.; SILVA, R. R.; MATEUS, R. G. Suplementação a pasto: disponibilidade e qualidade $\mathrm{x}$ níveis de suplementação x desempenho. Revista Brasileira de Zootecnia, Viçosa, MG, v. 38, p. 371-389, 2009. Suplemento Especial.

SILVA-MARQUES, R. P.; ZERVOUDAKIS, J. T.; HATAMOTO-ZERVOUDAKIS, L. K.; CABRAL. L. S.; ALEZANDRINO, E.; MELO, A. C. B.; SOARES, J. Q.; DONIDA, E. R.; SILVA, L. C. R. P. Suplementos múltiplos para novilhas de corte em pastejo no período seco. Semina: Ciências Agrárias, Londrina, v. 36, n. 1, p. 525-540, 2015.

SNEDECOR, G. W.; COCHRAN, W. G. Statistical methods. $8^{\text {th }}$ ed. Iowa: Iowa University Press, 1989. $503 \mathrm{p}$.

SNIFFEN, C. J.; O'CONNOR, J. D.; VAN SOEST, P. J.; FOX, D. G.; RUSSELL, J. B. A net carbohydrate and protein system for evaluating cattle diets: II. Carbohydrate and protein availability. Journal of Animal Science, Champaign, v. 70, n. 11, p. 35623577, 1992.

SAS - Statistical Analysis System. 1999. User's Guide: Statistics, version 8. Cary, NC: SAS Institute, 1999.

VAN SOEST, P. J. Nutritional ecology of the ruminants. $2^{\text {th }}$ ed. Ithaca: Cornell University, 1994. $476 \mathrm{p}$.

VAN SOEST, P. J.; ROBERTSON, J. B.; LEWIS, B. A. Methods for dietary fiber, neutral detergent fiber, and nonstarch polyssacharides in relation to animal nutrition. Journal of Animal Science, Champaign, v. 74, n. 10, p. 3583-3597, 1991.

VERBIC, J. Factors affecting microbial protein synthesis in the rumen with emphasis on diets containing forages. Gumpenstein, Germany: Viehwirtschaftliche Fachtagung, Milchproduktion und Rindermast. Gumpenstein, 2002. 10 p.

ZERVOUDAKIS, J. T.; SILVA, L. C. R. P.; SILVA, R. P.; JOSÉ NETO, A.; WERNER, J. F. K.; SILVA, R. G. F. Otimização do desempenho de bovinos por meio da suplementação à pasto. In: SIMPÓSIO MATOGROSSENSE DE BOVINOCULTURA DE CORTE, 1., 2011, Cuiabá. Anais... Cuiabá: I SIMBOV-MT, 2011. p. 151-189.

ZINN, R. A.; OWENS, F. N. Ruminal escape protein for lightweight feedlot calves. Journal of Animal Science, Champaign, v. 71, n. 10, p. $1677-$ 1687, 1993. 
